\title{
$\therefore$. \\ $=\quad$ Electrochemical Impregnation and Cycle Life of Lightweight Nickel Electrodes for Nickel-Hydrogen Cells
}

Doris L. Britton

Lewis Research Center

Cleveland, Ohio

Prepared for the

34th International Power Sources Conference

cosponsored by the U.S. Army and the Institute

of Electrical and Electronics Engineers

Cherry Hill, New Jersey, June 25-28, 1990

\section{N/SA}

(NASA-TM-103140) ELECTROCHEMICAL IMPPEGNATION AUN CYCLE LIFE UF LIGHTWFIGHT

NICKEL ELECTRODFS FOR NICKEL-HYDROGFN CELLS 


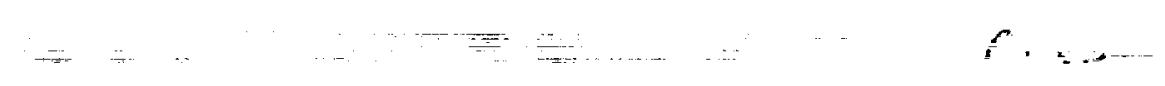

$=0$ 


\section{FOR NICKEL-HYDROGEN CELLS}

Doris L. Britton

National Aeronautics and Space Administration

Lewis Research Center

Cleveland, Ohio 44135

\section{Abstract}

Development of a high specific energy nickel electrode is the main goal of the lightweight nickel electrode program at the NASA Lewis Research Center. The approach has been to improve the nickel electrode by continuing combined in-house and contract efforts to develop a more efficient and lighter weight electrode for the nickel-hydrogen cell. Lightweight plaques are used as conductive supports for the nickel hydroxide active material. These plaques are commercial products that are fabricated into nickel electrodes by electrochemically impregnating them with active material. The electrodes are life cycle-tested in a low Earth orbit regime at 40 and 80 percent depths-of-discharge.

\section{INTRODUCTION}

The nickel electrode has been identified as the heaviest component of the nickel-hydrogen $\left(\mathrm{Ni}-\mathrm{H}_{2}\right)$ cell. As part of an overall goal to develop a high specific energy and specific volume $\mathrm{Ni}-\mathrm{H}_{2}$ cell for the low Earth erit (LEO) cycle regime, an improved lighter weight nickel electrode is being developed at the NASA Lew is Research Center. The approach has been to affect electrode improvements through continuing combined in-house and contract efforts. The state-of-the-art (SOA) heavy-sintered nickel plaque weight is about 58 percent of the nickel electrode weight. 1 The use of a lightweight nickel plaque in place of the SOA heavy-sintered plaque is expected to lead to improvements in specific energy of the nickel electrode. After some preliminary experiments, the Fibrex fiber plaque from National $S$ tandard was selected as one of the most promising support candidates for the active material. This material is formed by reducing and sintering fibers extruded from a mixture of nickel oxide and binding agents. ${ }^{2}$ A special type of Fibrex plaque layered with carbonyl nickel and cobalt powder is currently being impregnated and tested. This special type of material contains 50 parts nickel fiber, 35 parts nickel powder, and 15 parts cobalt powder. The plaques are available in different thicknesses, porosities and densities. Preliminary results showed that the porosity and thickness of these fibrex plaques affected the specific energy, initial performance and cycle life of the nickel electrodes.

\section{EXPERIMENTAL}

The plaques are electrochemically impregnated in an aqueous bath containing $1.5 \mathrm{M} \mathrm{Ni}\left(\mathrm{NO}_{3}\right)_{2}, 0.175 \mathrm{M}$ $\mathrm{Co}\left(\mathrm{NO}_{3}\right)_{2}$ and $0.075 \mathrm{M} \mathrm{NaNO}_{2}$ made acidic to a $\mathrm{pH}$ of 3 by the addition of 50 percent nitric acid $\left(\mathrm{HNO}_{3}\right)$. The the addition of 50 percent nitric acid $\left(\mathrm{HNO}_{3}\right)$. The ( 6 to $10 \mathrm{hr}$ ) and current densities $\left(45\right.$ to $\left.78 \mathrm{~mA} / \mathrm{cm}^{2}\right)$ to ( 6 to $10 \mathrm{hr}$ and current the conditions needed to obtain an active material loading of 1.6 to $2.0 \mathrm{~g} / \mathrm{cm}^{3}$ void. The $\mathrm{impreg-}$ nated plaques are formed by charging and discharging for $20 \mathrm{~min}$ at approximately the $3 \mathrm{C}$ rate. The formation process serves to remove impurities, which are chiefly nitrates, carried over from the impregnation bath.
The theoretical capacity is calculated from the weight of the active material in the electrode and the electrochemical equivalent of $0.289 \mathrm{~A}-\mathrm{hr} / \mathrm{g}$ of active material. The active material weight is calculated from the weight gained after the impregnation and formation procedures.

The electrodes are life cycle tested in a LEO regime in a flooded condition with 26 percent potassium hydroxide $(\mathrm{KOH})$ electrolyte. The voltage as a function of time is plotted continuously and capacities are measured regularly for the duration of the cycle life of the electrode. The percent utilization of the electrode is calculated by using the ratio of the measured capacity to the theoretical calculated capacity. Failure of the electrode is defined as the point where the discharge voltage degrades to $-0.2 \mathrm{~V}$ against a mercury/ mercuric oxide $(\mathrm{Hg} / \mathrm{HgO})$ reference electrode during the 35 min discharge.

Performance tests of the electrode at different discharge rates are intermittently conducted for the duration of the life cycle test. These tests include measurements at 5 different discharge rates: $0.5,1.0$, $1.37,2.0$ and $2.74 \mathrm{C}$ rates to $-0.2 \mathrm{~V}$ against the $\mathrm{Hg} / \mathrm{HgO}$ reference electrode after charging at a $\mathrm{C}$ rate for $80 \mathrm{~min}$.

At the end of life, the cell is disassembled and the components are visually inspected. After a thorough rinsing and drying, the nickel electrode is weighed and the thickness measured.

\section{RESULTS AND DISCUSSIONS}

One factor affecting the specific energy of a $\mathrm{Ni}-\mathrm{H}_{2}$ cell is the porosity of the nickel electrode. The specific energy of a $\mathrm{Ni}-\mathrm{H}_{2}$ cell will increase by replacing the SOA sintered nickel electrode with the highly porous lightweight nickel electrode. For example, the calculated specif ic energy of a $48 \mathrm{~A}-\mathrm{hr} \mathrm{Ni}-\mathrm{H}_{2}$ cell increases from $56.3 \mathrm{Wh} / \mathrm{kg}$ to $67.8 \mathrm{Wh} / \mathrm{kg}$ by replacing the nickel electrode made from an 80 percent porous SOA plaque with the lightweight nickel electrode made from thickness (30 mil) and loading level (1.8 $\mathrm{g} / \mathrm{cm}^{3}$ void). One advantage of the lightweight plaques over the SOA sintered plaque is that the lightweight plaques can easily be manufactured with much larger pore sizes than the SOA plaques. For instance, the Fibrex fiber/powder structures are commercially available in porosities up to 98 percent. On the other hand, commercial SOA sintered nickel plaques are available in porosities of 80 to 86 percent. A Fibrex nickel plaque, with $30 \mathrm{mil}$ thick and 93 percent porosity, was loaded with active material, at NASA Lewis, to $1.8 \mathrm{~g} / \mathrm{cm}^{3}$ void. This electrode will be called "93 percent porous/1.8-loaded" electrode. This electrode is currently cycling in a LEO regime at 80 percent DOD. The cycle regime consists of a $55-m i n$ charge at a $0.96 \mathrm{C}$ rate followed by a $35-m i n$ discharge at a $1.37 \mathrm{C}$ rate. The current cycle life data of this electrode is shown in Fig. 1. It took over 1000 cycles for this electrode to reach 100 percent utilization and another 500 cycles to reach 


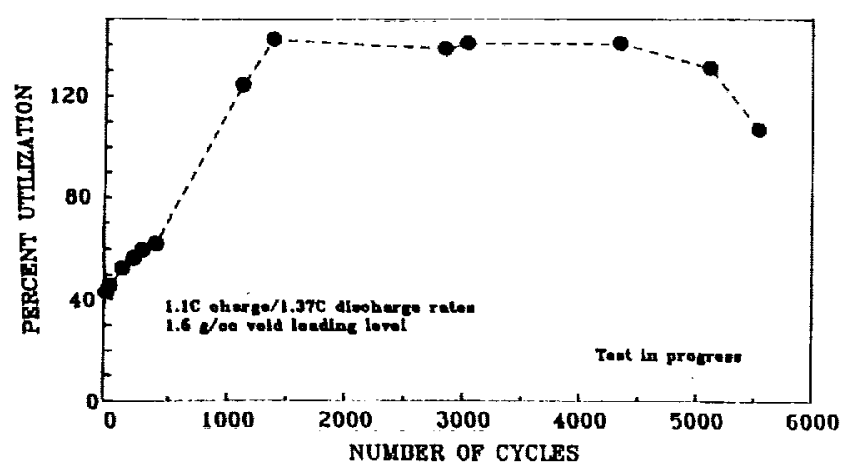

Figure 1. Utilization versus number of cycles of a $30 \mathrm{mil}$ thick, 90\% porous Fibrex electrode (made at LeRC; $1.8 \mathrm{~g} / \mathrm{cc}$ void loading).

its maximum utilization value of 140 percent. The ut $i-$ lization of the nickel electrode can exceed 100 percent since the valence change of the nickel ions during charge or discharge can be greater than 1 . The percent utilization values in this report were calculated based on a nickel ion valence change of 1 . This particular electrode has accumulated over 5600 cycles so far.

Another approach that will result in a higher specific energy of the $\mathrm{Ni}-\mathrm{H}_{2}$ cell is to use thick nickel electrodes. Utilizing fewer thick nickel electrodes will reduce the number of other components, e.g., hydrogen electrodes and separators. Two $80 \mathrm{mil}$ thick Fibrex plaques with 85 and 90 percent porosities were electrochemically impregnated using the aqueous bath at Eagle-Picher, Joplin, Missouri. Both electrodes were loaded to $1.6 \mathrm{~g} / \mathrm{cm}^{3}$ void of active material. The calculated specific energy of a $48 \mathrm{~A}-\mathrm{hr} \mathrm{Ni}-\mathrm{H}_{2}$ cell using these $80 \mathrm{mil}$ thick electrodes made from 85 and 90 percent porous plaques are 67.8 and $71.3 \mathrm{Wh} / \mathrm{kg}$, respectively. These electrodes were cycled, at NASA Lewis, in a LEO regime at 80 percent DOD. The cycle life of both electrodes are shown in Fig. 2, Neither electrode reached 100 percent utilization. The nickel electrode made from the less porous ( 85 percent) Fibrex nickel plaque (this electrode will be called " 85 percent porous/1.6-loaded" electrode) performed better than the electrode made from the more porous ( 90 percent) plaque (this electrode will be called "90 percent porous/1.6loaded" electrode). An initial utilization of about 72 percent for the less porous, 85 percent porous/1.6loaded, electrode was observed. It took this electrode about 595 cycles to reached its maximum utilization of 92 percent. The cycle test was terminated, at cycle 1120 , after losing about 24 percent of the maximum utilization value. On the other hand, the initial

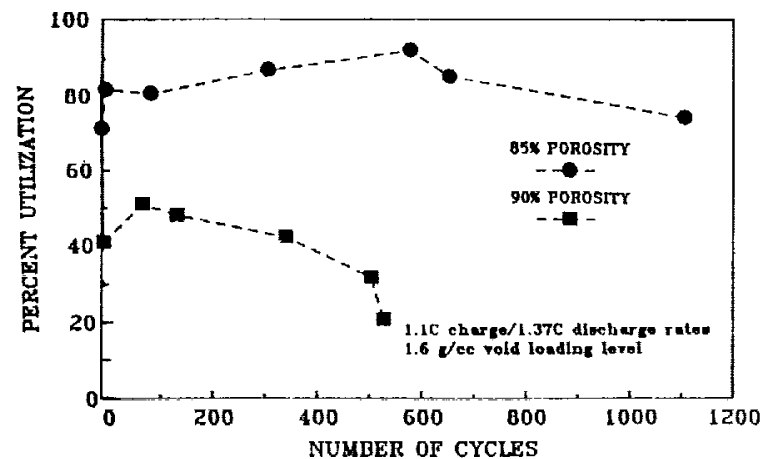

Figure 2. Utilization versus number of cycles of two 80 mil thick Fibrex electrodes with different porosities (made at Eagle-Picher). utilization of the more porous, 90 percent porous/1.6loaded, electrode was only 41 percent. A maximum ut $i$ lization of 51 percent was reached after 140 cycles. The utilization degraded to about 60 percent of its maximum value after 530 cycles, at which time the test was terminated.

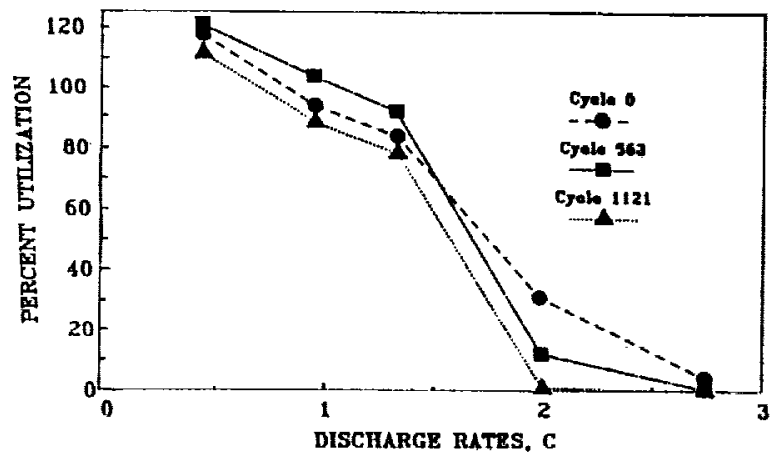

Figure 3. Performance of Fibrex electrode made from an 80 mil thick, 85\% porosity plaque.

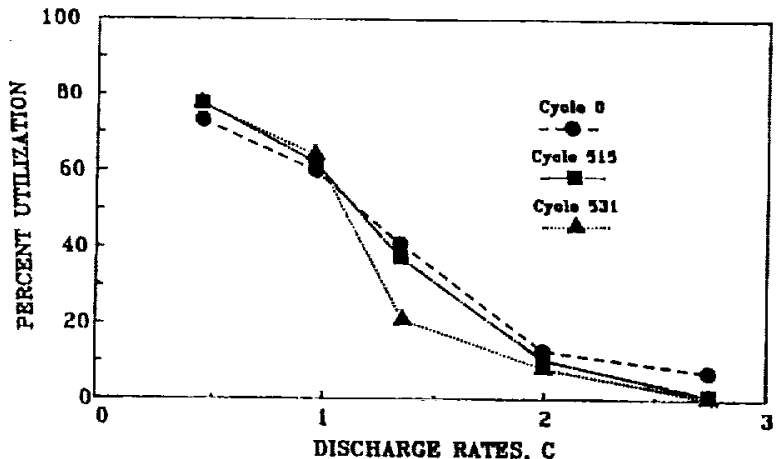

Figure 4. Performance of Fibrex electrode made from an 80 mil thick, 90\% porosity plaque.

Figures 3 and 4 depict the performance of both electrodes at the different discharge rates and cycles. The utilization of both electrodes were dependent upon the discharge rates and showed lower values at the higher rates. The utilization decreased severely as the discharge rate increased. The average utilization, at the high rate $(2.74 \mathrm{C})$ of both electrode was about 95 percent lower than at the low rate $(0.5 \mathrm{C})$. However, at the lower rate $(0.5 \mathrm{C})$, the utilization of neither electrode decreased. These results indicate that the failure of these electrodes was due mainly to the loss of high rate discharge capacity rather than the loss in total electrode capacity. Failure analysis indicated a weight lost of about 4 percent and an electrode expansion of about 18 percent for the less porous, 85 percent porous/1.6-loaded, electrode. In the case of the more porous, 90 percent porous/1.6-loaded, electrode, a severe weight lost and electrode expansion of about 17 and 27 percent, respectively, were observed. This significant expansion may have caused the extrusion of some active material out of the electrode which resulted in the loss of substantial amount of weight. The expansion and weight loss could be factors which affected the poor utilization and performance of the electrodes.

Loading thick, porous Fibrex plaques to a higher level would further increase the specific energy of the $\mathrm{Ni}-\mathrm{H}_{2}$ cell. A thick ( $80 \mathrm{mil}$ ) and porous (90 percent) Fibrex plaque was impregnated, at NASA Lewis, to a higher loading level of $1.8 \mathrm{~g} / \mathrm{cm}^{3}$ void. This electrode 
will be called a "90 percent porous/1.8-loaded" electrode. The calculated specific energy of a $48 \mathrm{~A}-\mathrm{hr}$ $\mathrm{Ni}-\mathrm{H}_{2}$ cell using this electrode is about $76.6 \mathrm{Wh} / \mathrm{kg}$. The cycle Iife (LEO, 80 percent DOD) and performance of this electrode were compared with the electrodes made from 85 and 90 percent porous plaques which were loaded to $1.6 \mathrm{~g} / \mathrm{cm}^{3}$ void discussed previously. Figure 5 shows

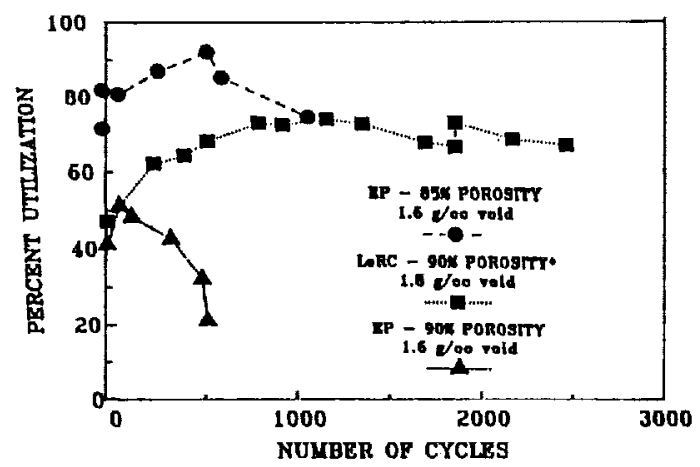

Figure 5. Utilization versus number of cycles of thick electrodes made from $85 \%$ and $90 \%$ porous plaques (made al Eagle-Plcher). [* reconditioned after 1917 cycles]

the comparison in the cycle life. The initial utiliza$t i$ on of the more porous and heavily loaded, 90 percent porous $/ 1.8$-loaded, electrode approached the value of the less porous and lightly loaded, 85 percent porous/ 1.6-loaded, electrode. However, as the heavily loaded 90 percent porous $/ 1.8$-loaded electrode cycled, the ut $i-$ lization increased gradually and reached a maximum value of about 74 percent at cycle 1220 . This maximum utilization value is 24 percent lower than the less porous and lightly loaded, 85 percent porous/1.6loaded, electrode. The cycle test of the 90 percent porous $/ 1.8$-loaded electrode was terminated with about 2500 cycles. A utilization decrease of about 10 percent was observed at this cycle.

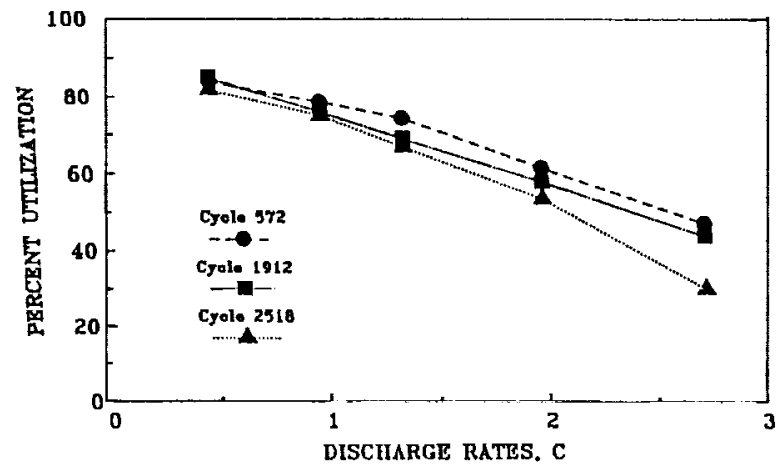

Figure 6. Performance of nickel electrode made from an 80 mil thick, 90\% porous Fibrex pleque (made at LeRC; $1.8 \mathrm{~g} / \mathrm{cc}$ void loading).

Figure 6 exhibits the performance, at different discharge rates and cycles, of the more porous and heavily loaded, 90 percent porous/1.8-loaded, electrode. The utilization values at the lower rate, $0.5 \mathrm{C}$, remain stable at about 84 percent from the beginning to the end of cycle life - about 40 percent lower than the value of the less porous and lightly loaded ( 85 percent porous $/ 1.6$-loaded) electrode. The loss in utilization as the discharge rate is increased is not as severe as those of the lightly loaded (1.6-loaded) electrodes even after 2500 cycles. Failure analys is of this electrode indicated a weight loss of about 11 percent and an electrode expansion of about 18 percent.

As was mentioned before, the use of heavily loaded, thick, porous Fibrex nickel electrodes will improve the specific energy of the $\mathrm{Ni}-\mathrm{H}_{2}$ cell. Preliminary test results of these electrodes, however, showed a reduction in the high rate capability of the nickel electrode. The current high rate cycle life and performance of the thick Fibrex nickel electrodes must be improved.

The cycle test of the more porous and lightly loaded, 90 percent porous/1.6-loaded, electrode made at Eagle-picher is currently cycling, in-house, using the LEO cycle regime at 40 percent DOD. The constant current cycling consists of charging at a $0.48 \mathrm{C}$ rate for $55 \mathrm{~min}$ and discharging at a $0.69 \mathrm{C}$ rate for $35 \mathrm{~min}$. The capacity is measured regularly by discharging at a $0.69 \mathrm{C}$ rate to $-0.2 \mathrm{~V}$ versus the $\mathrm{Hg} / \mathrm{HgO}$ electrode af ter charging at a $\mathrm{C}$ rate for $80 \mathrm{~min}$. The cycle life data of this electrode is shown in Fig. 7. An almost ideal behavior - quick rise and stable utilization - was exhibited at this rate. This electrode has accumulated over 1100 cycles so far with a steady and gradual increase in utilization.

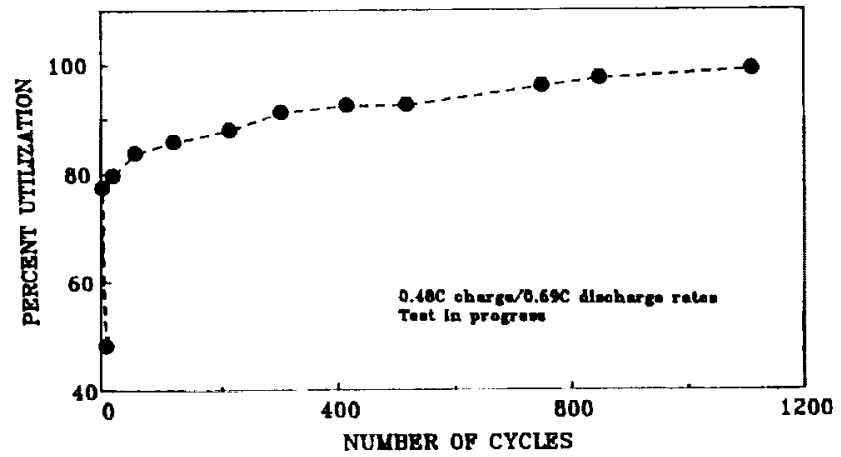

Figure 7. Utillzation vergus number of cycles of thick electrode made from a $90 \%$ porous Fibrex plaque and cycled in a LEO regime at $40 \%$ DOD.

The changes in morphology and active material deposition of the new and cycled electrodes will be studied using SEM photographs. The pore size distribution curves will also be examined to determined any changes in the pore sizes of the cycled electrodes.

Cycle tests at the lower depths of discharge (40 and 60 percent) of the Fibrex electrodes will be continued and compared with the electrodes cycled at 80 percent DOD.

Improvement of the initial utilization of the lightweight electrodes will be investigated by using different pretreatment, impregnation and formation procedures.

0 ther lightweight plaques are also being investigated. A lightweight nickel porous metal, Retec, from Eltech Systems Corporation is currently being impregnated and tested. Other candidate lightweight plaques are the nickel plated plastic that was developed at NASA Lewis using a polyvinyl chloride material from Amerace Corp, nickel felt and fibers from Sorapec (France), and the machined sintered nickel fiber mats from Nippon Seisen (Japan). 


\section{CONCLUSIONS}

The development and cycle life testing of Fibrex nickel electrode have demonstrated the feasibility of an improved and higher specific energy nickel electrode. Electrochemical impregnation of lightweight fiber mats has produced loading levels comparable to SOA electrodes. Early cycle life testing of a heavilyloaded, thick and porous Fibrex nickel electrode has shown promising results when cycled at 40 percent DOD. More research is required to improve performance at deep-depths-of-discharge. Investigations continue on achieving optimal pretreatment, impregnation and formation methods to provide for high rate applications.

\section{REFERENCES}

1. Lim, H, Hughes Aircraft Company, private communication.

2. Colucci, S.L., "System for Stretch Casting Filamentary Shaped Bodies," U.S. Patent 4,312,670, Jan. 26, 1982 . 


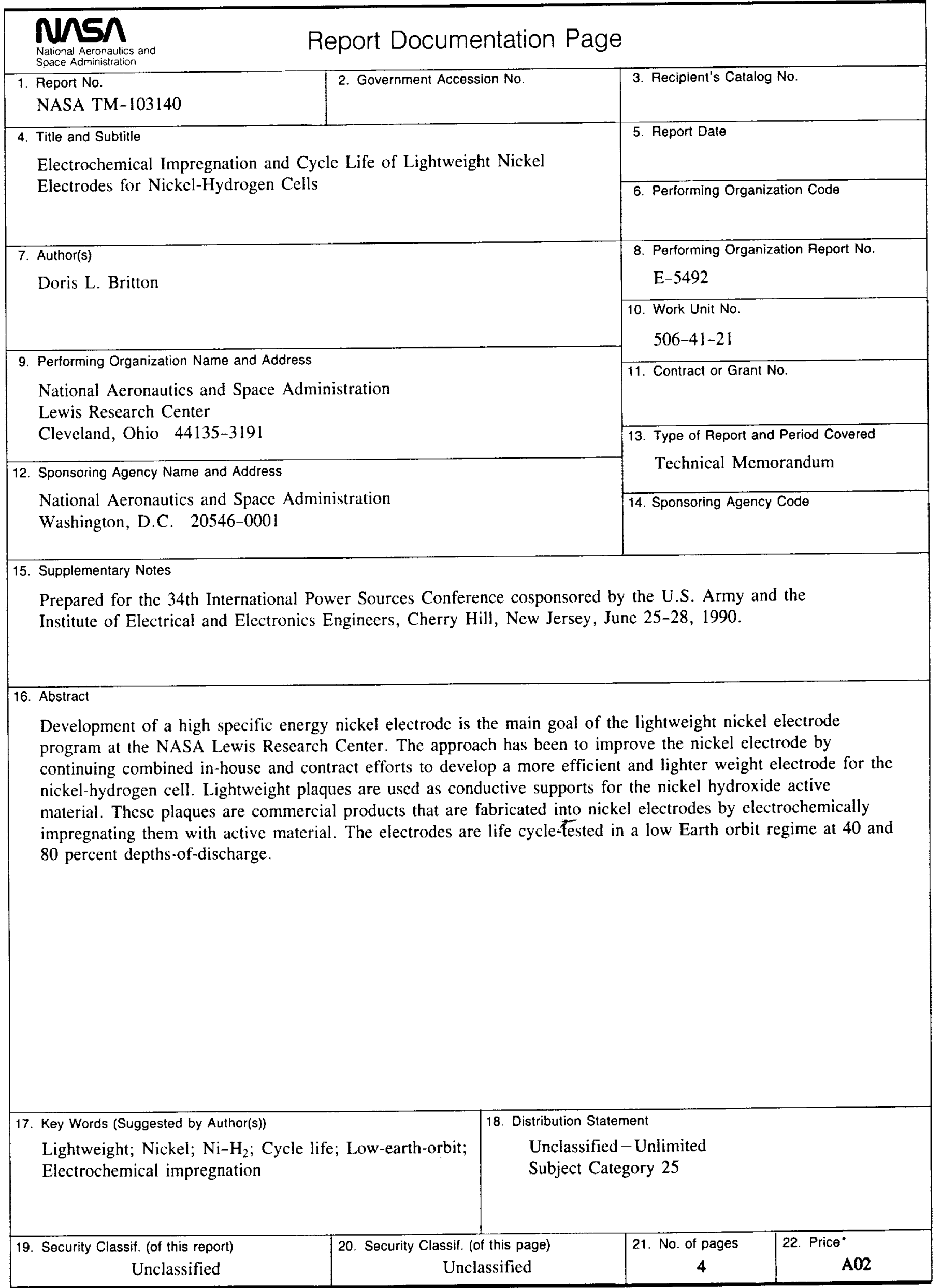


. 